Research report

\title{
Promoting the avoidance of high-calorie snacks. The role of temporal message framing and eating self-efficacy
}

\author{
Susan Churchill ${ }^{\mathrm{a}, *}$, Anna Good ${ }^{\mathrm{b}}$, Louisa Pavey ${ }^{\mathrm{c}}$ \\ a University of Chichester, College Lane, Chichester, West Sussex, P019 6PE, United Kingdom \\ b University of Sussex, Brighton, East Sussex, BN1 9RH, United Kingdom \\ c Kingston University, Penrhyn Rd, Kingston upon Thames, Surrey, KT1 2EE, United Kingdom
}

\section{A R T I C L E I N F O}

\section{Article history:}

Received 21 March 2014

Received in revised form 5 May 2014

Accepted 8 May 2014

Available online 16 May 2014

\section{Keywords:}

Snacking

Eating self-efficacy

Persuasive communication

Message framing

Temporal framing

\begin{abstract}
A B S T R A C T
Background: Message framing outcomes of healthy behaviours as occurring 'every day' vs. 'every year' can influence the temporal proximity and perceived likelihood of these outcomes. However, it is not known how pre-existing beliefs such as confidence in one's ability to perform health-related behaviour interact with such messages. Objective: The purpose of this research was to investigate whether eating self-efficacy moderates the effect of temporal framing (day-frame vs. year-frame) on snacking behaviour. Methods: Participants $(N=95)$ completed the short form of the Weight Efficacy Lifestyle Questionnaire (WEL-SF) and read either a day-framed or year-framed message about the health benefits associated with avoiding snacking. Consumption of snacks was reported 7 days later. Findings: For those with low levels of eating self-efficacy (WEL-SF score $<4.3$ on a 7-point response scale), the year-framed message was associated with lower levels of snacking than the day-framed message. Discussion: The current research identifies a key role for eating self-efficacy in shaping recipients' responses to temporally framed messages about the health benefits associated with the avoidance of snacking.
\end{abstract}

(c) 2014 Elsevier Ltd. All rights reserved.

\section{Introduction}

The role of diet in excessive weight gain, obesity, and chronic diseases such as cardiovascular disease, diabetes, and some forms of cancer, is well documented (Boffetta et al., 2010; Brannon \& Feist, 2009; Forslund, Torgerson, Sjöström, \& Lindroos, 2005; Gandini, Merzenich, Robertson, \& Boyle, 2000; Hooper et al., 2001; Joshipura et al., 2001; Kopelman, 2007; Liu, 2003; Lobstein, Rigby, \& Leach, 2005; Ness \& Powles, 1997; Wiseman, 2008), with a high frequency of snacking recognised as a significant contributor to the obesity epidemic (Miller, Benelam, Stanner, \& Buttriss, 2013). There has been widespread dissemination of messages about the benefits of healthy diet. However, the current prevalence of eating-related problems (Tabassum, 2009) suggests that there is more to be done to develop effective health communication in this area.

The current study focuses on a simple manipulation of the way in which the benefits of healthy diet are framed. More specifically, in this investigation we turn to the conceptual rationale based on temporal framing (Chandran \& Menon, 2004; Lo, Smith, Taylor, Good, \& von Wagner, 2012) and explore the effects of day-framed and

\footnotetext{
* Corresponding author.

E-mail address: s.churchill@chi.ac.uk (S. Churchill).
}

year-framed messages encouraging the avoidance of snacking. Extending current knowledge, we explore the potential moderating role of eating self-efficacy in this context.

\section{Temporal framing}

There are a number of approaches available to guide health educators in the development of persuasive communications (Chaiken \& Eagly, 1989; Chaiken \& Maheswaran, 1994; Kahneman \& Tversky, 1979; Levin, Schneider, \& Gaeth, 1998; Petty \& Cacioppo, 1986; Rothman, Bartels, Wlaschin, \& Salovey, 2006; Rothman \& Salovey, 1997; Rothman, Wlaschin, Bartels, Latimer, \& Salovey, 2008; Tversky \& Kahneman, 1981). One promising strategy, drawing on Construal Level Theory (Trope \& Liberman, 2000, 2003, 2010), concerns temporal framing (Chandran \& Menon, 2004). Temporal framing is the application of a time frame to a particular outcome such as 'many people dying from heart disease'. For example, comparisons can be made between messages containing the sentence "every day a significant number of people suffer the consequences of heart disease" and "every year a significant number of people suffer the consequences of heart disease". While objectively, the time frame does not convey information about the temporal distance of the events they describe (heart disease), it has been argued that the day and year frames 'trigger disparate subjective temporal perceptions that systematically affect judgments of risk', with day frames 
associated with events that are closer in time (more proximal), and thus more concrete and probable than those associated with a year frame (Chandran \& Menon, 2004; p. 376).

Chandran and Menon (2004) propose that day frames will be more effective within negative-valence messages because the threats to health appear more concrete and imminent. In contrast, year frames are expected to be more effective within positive-valence messages where avoidance of a health threat seems a distant prospect, heightening the perception of risk to health in the immediate future and increasing individuals' motivation to act. While the research in this area is limited, the findings have supported these assertions (Chandran \& Menon, 2004; Kees, 2011; Lo et al., 2012). It appears that temporal framing may be a simple and effective technique for enhancing the persuasive impact of health messages. However, many questions remain about whether individual differences moderate these effects. It is possible that individuals' level of self-efficacy prior to exposure to health communications is influential. In particular, it may be more challenging to manipulate perceptions of whether health threats can be avoided amongst those who are confident in their ability to perform the targeted behaviour. The effects of temporal framing within gain-framed messages depend on manipulating the proximity and concreteness of avoiding a threat, and consequently, self-efficacy is likely to play an important moderating role.

\section{The moderating role of self-efficacy}

In both correlational and experimental studies, confidence in one's ability to engage in recommended behaviour has been shown to be a strong predictor of whether this behaviour is achieved (Bandura, 1977, 1986, 1997, 2001; Bandura \& Locke, 2003; Guillaumie, Godin, \& Vézina-Im, 2010; Povey, Conner, Sparks, James, \& Shepherd, 2000; Salovey, Rothman, \& Rodin, 1998; Schwarzer, 2008; van 't Riet, Ruiter, Werrij, \& de Vries, 2009, 2010; Werrij, Ruiter, van 't Riet, \& de Vries, 2011).

Self-efficacy is an important moderator of the effects of interventions that target healthy lifestyles (Saksvig et al., 2005; Wangberg, 2008); and in the context of dietary behaviour, research has shown that individuals reporting higher levels of self-efficacy are less likely to snack (Masalu \& Åstrøm, 2001), more likely to act on their intentions to eat healthy foods (Gutiérrez-Doña, Lippke, Renner, Kwon, \& Schwarzer, 2009; Richert et al., 2010; Schwarzer, 2008), and more successful in achieving weight loss (Brownell \& Cohen, 1995; Byrne, 2002; Strecher, DeVellis, Becker, \& Rosenstock, 1986; Wadden \& Letizia, 1992). Novel approaches are thus required to promote behaviour change amongst those lower in self-efficacy.

\section{The current study}

The current study is the first to test the moderating effect of selfefficacy on temporally framed (day-framed vs. year-framed) messages emphasising the health benefits associated with the avoidance of snacking at work ${ }^{1}$. Chandran and Menon (2004) argue that when

\footnotetext{
1 The use of a positive-valenced message following a statement about the health consequences associated with unhealthy diet is in keeping with messages typically used to encourage healthy dietary choices. For example, in the UK, the NHS Choices website states that 'eating a healthy, balanced diet is an important part of maintaining good health, and can help you feel your best'. Previous research also indicates that the effectiveness of gain-framed health messages when encouraging 'safe' behaviours that are characterised typically by little 'risk' (e.g. dietary behaviour, exercise, dental flossing) and which are likely to result in a healthy outcome (see Rothman et al., 2006). Loss-framed messages (vs. gain-framed messages) are typically more persuasive when encouraging behaviours that may be construed as 'risky' to perform (e.g. mammography, HIV screening) given their potential to detect the presence of a serious health problem (Rothman et al., 2006; Rothman \& Salovey, 1997).
}

an outcome is framed positively, year-framed messages make the health hazard appear more of a threat than day-frame messages. Hence, we hypothesised that for participants reporting low levels of eating self-efficacy there would be an effect of temporal framing on the avoidance of snacking, with those reading the year-framed messages about the benefits of reduced snacking reporting less snacking behaviour than those reading the day-framed messages. In contrast, we expected to find that if message recipients are confident that they are capable of exerting control over eating behaviour (high eating self-efficacy), then health communications about the consequences of adopting or not adopting a healthy diet will be equally beneficial in both day- and year-frame conditions. Those reporting high self-efficacy should be less susceptible to manipulations that are intended to alter perception of whether avoidance of risk is proximal and concrete or distant and abstract.

\section{Method}

\section{Participants}

One hundred forty-six participants completed the Time 1 measures, 51 failed to respond at Time 2, representing an attrition rate of 35\%. Participants were staff at a university in the South of England (74 female) aged 22-66 $(M=42.44 ; S D=11.07)$. Body mass index (BMI) ranged from 17.92 to 37.28 , with an average at the higher end of the 21-25 normal BMI category $(M=24.37 ; S D=3.77)$.

\section{Design and procedure}

The study employed a randomised prospective design, involving two waves of data collection ${ }^{2}$. University staff responded to an email inviting them to participate in an on-line survey about workbased eating behaviour, with the offer of a free lunch-time salad as incentive. At Time 1, participants were randomly assigned to receive either a day-framed or year-framed message about the benefits of avoiding eating high-calorie snacks. The use of these time frames is in keeping with previous studies in this area (e.g. Chandran \& Menon, 2004; Lo et al., 2012). Allocation was based on a computergenerated numbers list. Participants completed Time 2 measures 7 days later.

\section{Measures and manipulations}

\section{Demographic information}

Participants were asked to indicate their age, gender, weight, and height. Body mass index (BMI) was calculated for each participant: $\mathrm{BMI}=$ weight $(\mathrm{kg}) /$ height $(\mathrm{m})^{3}$.

\section{Baseline snacking behaviour}

Following Luszczynska, Tryburcy, and Schwarzer (2007), baseline snacking behavior was measured with a single item 'In the last 7 days at work, how many high-calorie snacks did you eat?' Participants were provided with examples of snack foods (e.g. chocolate, crisps, salted nuts), and participants were given an open text box in which to respond.

\footnotetext{
2 Participants were invited to complete a second follow-up questionnaire, one month after completion of the initial follow up; receiving the offer of a free lunchtime salad as incentive to participate. The number of participants completing this survey was too small to conduct any further meaningful analyses.

3 It should be noted that subjective (self-reported) measures assessing height and weight were used to calculate body mass index (BMI).
} 
Table 1

Means and standard deviations of the study variables by condition.

\begin{tabular}{lccc}
\hline & $\begin{array}{l}\text { Day-frame } \\
M(\mathrm{SD})\end{array}$ & $\begin{array}{l}\text { Year-frame } \\
M(\mathrm{SD})\end{array}$ & $\begin{array}{l}\text { Whole sample } \\
M(\mathrm{SD})\end{array}$ \\
\hline Snacking & $3.31(3.41)$ & $2.64(2.88)$ & $3.00(3.18)$ \\
Baseline snacking & $4.50(4.23)$ & $4.04(3.62)$ & $4.29(3.95)$ \\
Eating self-efficacy & $4.39(1.14)$ & $4.53(1.09)$ & $4.45(1.11)$ \\
Age & $41.62(10.49)$ & $43.36(11.27)$ & $42.44(11.07)$ \\
BMI & $23.65(3.30)$ & $25.15(4.11)$ & $24.36(3.77)$ \\
\hline
\end{tabular}

\section{Eating self-efficacy}

Individual differences in eating self-efficacy at baseline were measured using the 8-item short form of the Weight Efficacy Lifestyle Questionnaire (WEL-SF; Ames, Heckman, Grothe, \& Clark, 2012), e.g. 'I can resist eating when I am anxious (or nervous)', 'I can resist eating when I am depressed (or down), 'I can resist eating even when others are pressuring me to eat', measured on a scale from 1 ('disagree strongly') to 7 ('agree strongly'), $\alpha=.88$. The WEL-SF is designed to measure self-confidence for controlling eating behaviour in particular situations.

The framed health messages. Participants were asked to read a health message which detailed the benefits of avoiding snacking (following messages by Pavey \& Churchill, in press). In order to manipulate temporal frame, the health consequences of snacking behaviour were presented as occurring either every day or every year. The dayframed message read: 'EVERY DAY a significant number of people suffer the consequences of failing to eat healthily. For example, evidence suggests that people who avoid eating high-calorie snacks, compared to those who do not, are at lower risk of many serious life-threatening diseases and gain several potential health benefits. People who avoid eating high-calorie snacks have a LOWER RISK of: Heart disease, Stroke, High blood pressure, Type 2 diabetes, cancers (e.g. bowel cancer). Avoiding eating high-calorie snacks can also give you other HEALTH BENEFITS, such as: healthy looking skin and hair, healthy weight, and increased energy and vitality. We would like you to avoid eating highcalorie snacks at work over the next 7 days'. The words 'EVERY DAY' were replaced with 'EVERY YEAR' in the year-framed condition.

Time 2 snacking behaviour was measured using the same item as at baseline.

\section{Data analysis}

Table 1 summarises the descriptive statistics of the sample. Chisquare analysis and one-way ANOVAs revealed no significant differences between those in the day-frame condition $(n=51)$ and those in the year-framed condition $(n=44)$ in terms of gender, age, BMI, baseline snacking behaviour, and eating self-efficacy (all $p$ 's > .30). Chi-squared analysis and one-way ANOVAs revealed no significant differences on study variables between those responding at Time 2 and non-responders (all p's > .68). Bivariate correlations between baseline snacking behaviour, eating self-efficacy, age, BMI and Time 2 snacking behaviour are given in Table 2 .

Table 2

Bivariate correlations between variables.

\begin{tabular}{lcccc}
\hline & 1 & 2 & 3 & 4 \\
\hline 1. Snacking behaviour (Time 2) & & & & \\
2. Baseline snacking & $.56^{* * *}$ & & & \\
3. Eating self-efficacy & $-.22^{*}$ & $-.23^{*}$ & & \\
4. Age & -.04 & $-.20^{*}$ & .01 & \\
5. BMI & -.02 & .05 & $-.40^{* *}$ & $.17^{*}$ \\
\hline${ }^{*} p<.05 ;{ }^{* *} p<0.01 ;{ }^{* * *} p<.001$. & & & &
\end{tabular}

Moderated hierarchical multiple regression analysis was used to predict snacking behaviour. Continuous variables were standardised and categorical variables were dummy coded prior to analysis. We report and interpret the unstandardised regression coefficients. Gender (dummy coded with men allocated a value of 0 , and women a value of 1 ), age, BMI, and baseline snacking behaviour were entered at step 1 to control for any effect of these variables on snacking behaviour. Condition (dummy coded with the day-frame message condition allocated a value of 0 , and the yearframe message condition a value of 1 ) was entered at step 2 to determine whether the experimental manipulation had an impact on snacking behaviour, followed by eating self-efficacy at step 3. Lastly, the interaction terms between condition and eating self-efficacy were entered at step 4 to explore whether any effect of the experimental manipulation on snacking behaviour was moderated by eating self-efficacy. Pending this interaction being significant, we planned to use the Johnson-Neyman technique to identify the particular levels of snacking at which there were significant differences according to condition (Johnson \& Neyman, 1936; see Bauer \& Curran, 2005; Hayes \& Matthes, 2009).

\section{Results}

Predicting snacking behaviour. Gender, age, BMI, and baseline snacking behaviour entered at step 1, predicted $33 \%$ of the variance in snacking behaviour, $F(4,75)=9.11, p=.0001$. Inspection of the individual $b$ values at this step revealed that baseline snacking ( $b=1.79, p=.0001$ ) emerged as a significant predictor, with those eating more snacks in the past reporting greater levels of snacking.

Condition, entered at step 2, led to a marginal increase in the amount of variance explained by the model, $\Delta R^{2}=.03, F(1,74)=3.00$, $p=.09$. Entering eating self-efficacy at step 3 failed to contribute significantly to the explained variance in snacking, $\Delta R^{2}=.01$, $F(1,73)=1.45, p=.23$.

As predicted, the inclusion of the eating self-efficacy $\times$ condition interaction term at step 4 significantly increased the overall amount of the variance explained by the model, $b=1.23, p=.05$, $\Delta R^{2}=.03, F(1,72)=4.02, p=.05$, and the final model accounted for $40 \%$ of the variance in behaviour, $F(7,72)=6.84, p<.0001$ (see Table 3 ). Figure 1 depicts the regressions of behaviour on eating self-efficacy for those in the day-frame and year-frame conditions respectively. The shaded area highlights the region of significance identified using the Johnson-Neyman techique (Johnson \& Neyman, 1936). As predicted, there was no significant effect of the temporal frame condition amongst those reporting higher levels of eating self-efficacy. However, amongst those with lower eating self-efficacy (scoring 4.3 or less on a 7-point response scale 1 ['disagree strongly'] to 7 ['agree strongly']) participants in the year-frame condition reported less snacking over the previous 7 days than those in the year-frame condition. This cut-off point is close to the mean score of 4.45 .

\section{Discussion}

Previous research has shown that simple temporal framing manipulations can be used to increase the persuasiveness of health messages (Chandran \& Menon, 2004; Kees, 2011; Lo et al., 2012). The current study extends knowledge in this area by testing the prediction that individuals' perceived capabilities to control eating behaviour (eating self-efficacy) would moderate the effects of temporal framing within messages about the benefits of avoiding snacking.

Results revealed a significant interaction between temporal framing and eating self-efficacy. As predicted, there was no effect of temporal frame for those reporting sufficient confidence in their ability to control eating behaviour; only those with lower expec- 
Table 3

Hierarchical regressions of snacking behaviour on message framing and eating self-efficacy.

\begin{tabular}{|c|c|c|c|c|c|}
\hline Step & Variables entered & $B$ (Step1) & $B$ (Step2) & $B$ (Step3) & $B$ (Step4) \\
\hline \multirow[t]{4}{*}{1} & Gender & -1.01 & -.98 & -1.09 & -1.06 \\
\hline & Age & .25 & .33 & .45 & .51 \\
\hline & BMI & -.19 & -.10 & -.29 & -.23 \\
\hline & Baseline snacking & $1.79^{* * * *}$ & $1.78^{* * *}$ & $1.70^{* * * *}$ & 1.70 \\
\hline 2 & $\begin{array}{l}\text { Condition (day- vs. year- } \\
\text { framed messages) }\end{array}$ & & $-1.01^{\dagger}$ & -.98 & -1.06 \\
\hline 3 & Eating self-efficacy & & & -.45 & $-.10^{*}$ \\
\hline 4 & Condition $\times$ eating self-efficacy & & & & $1.24^{*}$ \\
\hline$R^{2}$ & & .33 & .35 & .37 & .40 \\
\hline$\Delta R^{2}$ & & .33 & .03 & .01 & .03 \\
\hline$\Delta F$ & & $9.11^{* * *}$ & 3.00 & 1.45 & $4.02^{*}$ \\
\hline
\end{tabular}

${ }^{\dagger}<.10 ;{ }^{*} p<.05 ;{ }^{* *} p<0.01 ;{ }^{* * *} p<.001$.

tations about their ability to control eating behaviour appeared to respond to the manipulation. For those reporting lower levels of eating self-efficacy, findings were in line with previous research demonstrating the effect of temporal framing within positive valence messages (Chandran \& Menon, 2004; Lo et al., 2012). Among these participants, those exposed to the year-framed message reported eating less snacks than those exposed to the day-framed message.

Chandran and Menon (2004) contend that positive-valence yearframed messages make avoidance of a health threat feel more distant - heightening threat in the immediate future and increasing individuals' motivation to act. Indeed, their study on heart disease showed that a health-benefit presented in a year frame was associated with higher perceived risk and worry about the health threat. We did not measure risk perceptions in the current study. However, it is likely that participants with less confidence in their ability to control the targeted behaviour were more responsive to the message implying that avoidance of the health risk was a more distant and less easily achieved prospect. Previous research has indicated that health messages are most effective when they are framed to fit recipients' pre-existing beliefs or preferences (e.g. Mann, Sherman, \& Updegraff, 2004; Spiegel, Grant-Pillow, \& Higgins, 2004). Further research is needed to test this theory in the current domain, in particular, whether the fit between the beliefs of those low in eating self-efficacy and the year-framed messages resulted in heightened risk perceptions, and greater receptiveness to and acceptance of the health recommendations.

It is important to note that the findings of this study may be limited by the reliance on self-report measures of snacking behaviour

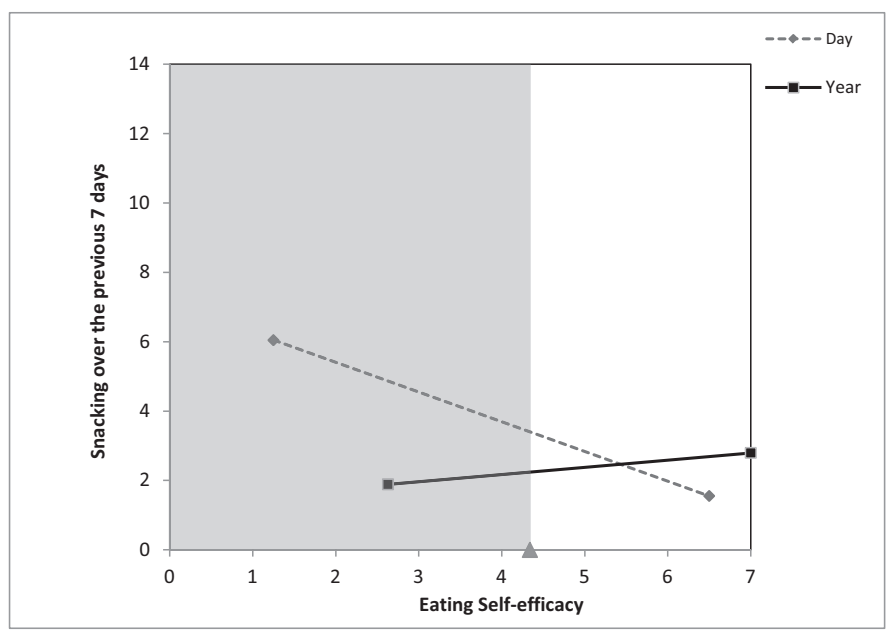

Fig 1. The effect of temporal frame condition (day vs. year) on snacking at different levels of eating self-efficacy. over the 7 days post-intervention. Though underreporting of dietary intake is often problematic (Huang, Roberts, Howarth, \& McCrory, 2005), this should not have occurred differentially across the experimental conditions. Nevertheless, it would be prudent to replicate the study using a more reliable measure of snacking (e.g. a food diary). Self-report measures of individual difference variables such as eating self-efficacy also rely on the honesty and insight of the participants completing the questionnaire, and may be susceptible to processes associated with self-deception, ego enhancement and ego protection (Chan, 2009). Thus, it would also be constructive to explore whether the findings of the current study can be replicated using a measure of eating self-efficacy that does not rely on self-report, such as an implicit measure of food-specific inhibitory control (e.g. Houben \& Jansen, 2011; Houben, Nederkoorn, \& Jansen, 2013).

A further potential limitation is the high attrition rate. It is not uncommon to find attrition rates this high in on-line studies (Etter, 2006; Eysenbach, 2005; van 't Riet et al., 2010). Findings revealed no significant differences on study variables between responders and non-responders. However, it is possible that the high attrition rate limits the generalisability of the study findings and this highlights the need for replication. Future research should also investigate the longer-term effects of temporal framing on avoidance of snacking since long-term maintenance of dietary change is difficult to achieve (Kumanyika et al., 2000).

Our findings suggest that individuals low in self-efficacy, who typically have the poorest health behaviours, may be more likely to make healthier choices if they receive messages including an 'every year' temporal frame. It seems plausible that eating self-efficacy might moderate the effectiveness of year-framed messages that are designed to encourage the avoidance of other risky dietary behaviour For example, eating self-efficacy might moderate the effectiveness of year-framed messages that advocate the benefits of 'approach behaviour' such as fruit and vegetable consumption. This represents a profitable area for future research. Further research may also explore the moderating effect of self-efficacy on temporally framed health messages encouraging performance of non-dietary related behaviours, e.g. sunscreen use, smoking cessation and alcohol reduction.

\section{Conclusions}

Persuading people to adopt healthy dietary behaviours would substantially reduce illness morbidity and premature death in the UK, and increase work productivity. The results of the current study suggest that the characteristics of audience members can shape receptivity to persuasive health communication. In order to provide people with health information about diet-related behaviour that is most effective, persuasive appeals should be tailored to both the temporal context and to individual difference variables such as selfefficacy. Furthermore, in the light of the findings in the current study, 
it is evident that the effects of temporal framing (day vs. year) should not be presumed if potentially important moderators such as eating self-efficacy have not been considered.

\section{References}

Ames, G. E., Heckman, M. G., Grothe, K. B., \& Clark, M. M. (2012). Eating self-efficacy. Development of a short-form WEL. Eating Behaviors, 13(4), 375-378.

Bandura, A. (1977). Self-efficacy. Toward a unifying theory of behavioral change. Psychological Review, 84(2), 191

Bandura, A. (1986). The explanatory and predictive scope of self-efficacy theory. Journal of Social and Clinical Psychology, 4(3), 359-373.

Bandura, A. (1997). Self-efficacy. The exercise of control. New York: Freeman.

Bandura, A. (2001). Social cognitive theory. An agentic perspective. Annual Review of Psychology, 52(1), 1-26.

Bandura, A., \& Locke, E. A. (2003). Negative self-efficacy and goal effects revisited. The Journal of Applied Psychology, 88(1), 87.

Bauer, D. J., \& Curran, P. J. (2005). Probing interactions in fixed and multilevel regression. Inferential and graphical techniques. Multivariate Behavioral Research, 40(3), 373-400. doi:10.1207/s15327906mbr4003 5.

Boffetta, P., Couto, E., Wichmann, J., Ferrari, P., Trichopoulos, D., Bueno-de-Mesquita, H. B., et al. (2010). Fruit and vegetable intake and overall cancer risk in the European Prospective Investigation into Cancer and Nutrition (EPIC). Journal of the National Cancer Institute, 102(8), 529-537.

Brannon, L., \& Feist, J. (2009). Health psychology. An introduction to behavior and health. Cengage Learning.

Brownell, K. D., \& Cohen, L. R. (1995). Adherence to dietary regimens 2. Components of effective interventions. Behavioral Medicine, 20(4), 155-164.

Byrne, S. M. (2002). Psychological aspects of weight maintenance and relapse in obesity. Journal of Psychosomatic Research, 53(5), 1029-1036.

Chaiken, S., \& Eagly, A. H. (1989). Heuristic and systematic information processing within and beyond the persuasion context. In J. S. Uleman \& J. A. Bargh (Eds.), Unintended thought (pp. 212-252). New York: Guilford Press.

Chaiken, S., \& Maheswaran, D. (1994). Heuristic processing can bias systematic processing. Effects of source credibility, argument ambiguity, and task importance on attitude judgment. Journal of Personality and Social Psychology, 66(3), 460 .

Chan, D. (2009). So why ask me? Are self-report data really that bad? In C. E. Lance \& R. J. Vandenberg (Eds.), Statistical and methodological myths and urban legends: Doctrine, verity and fable in the organizational and social sciences (pp. 309-336). New York, NY: Routledge.

Chandran, S., \& Menon, G. (2004). When a day means more than a year. Effects of temporal framing on judgments of health risk. The Journal of Consumer Research, 31, 375-389. doi:10.1086/422116.

Etter, J. F. (2006). Internet-based smoking cessation programs. International Journal of Medical Informatics, 75(1), 110-116.

Eysenbach, G. (2005). The law of attrition. Journal of Medical Internet Research, 7(1).

Forslund, H. B., Torgerson, J. S., Sjöström, L., \& Lindroos, A. K. (2005). Snacking frequency in relation to energy intake and food choices in obese men and women compared to a reference population. International Journal of Obesity, 6, 711719.

Gandini, S., Merzenich, H., Robertson, C., \& Boyle, P. (2000). Meta-analysis of studies on breast cancer risk and diet. The role of fruit and vegetable consumption and the intake of associated micronutrients. European Journal of Cancer, 36(5), 636-646.

Guillaumie, L., Godin, G., \& Vézina-Im, L. A. (2010). Psychosocial determinants of fruit and vegetable intake in adult population. A systematic review. The International Journal of Behavioral Nutrition and Physical Activity, 7, 12.

Gutiérrez-Doña, B., Lippke, S., Renner, B., Kwon, S., \& Schwarzer, R. (2009). Self-efficacy and planning predict dietary behaviors in Costa Rican and South Korean women. Two moderated mediation analyses. Applied Psychology: Health and Well-Being, 1(1), 91-104.

Hayes, A. F., \& Matthes, J. (2009). Computational procedures for probing interactions in OLS and logistic regression. SPSS and SAS implementations. Behavior Research Methods, 41(3), 924-936. doi:10.3758/BRM.41.3.924

Hooper, L., Summerbell, C. D., Higgins, J., Thompson, R. L., Capps, N. E., Smith, G. D., et al. (2001). Dietary fat intake and prevention of cardiovascular disease. Systematic review. British Medical Journal, 322(7289), 757-763.

Houben, K., \& Jansen, A. (2011). Training inhibitory control. A recipe for resisting sweet temptations. Appetite, 56(2), 345-349.

Houben, K., Nederkoorn, C., \& Jansen, A. (2013). Eating on impulse. The relation between overweight and food-specific inhibitory control. Obesity, E6-E8.

Huang, T. T. K., Roberts, S. B., Howarth, N. C., \& McCrory, M. A. (2005). Effect of screening out implausible energy intake reports on relationships between diet and BMI. Obesity Research, 13(7), 1205-1217.

Johnson, P. O., \& Neyman, J. (1936). Tests of certain linear hypotheses and their application to some educational problems. Statistical Research Memoirs.

Joshipura, K. J., Hu, F. B., Manson, J. E., Stampfer, M. J., Rimm, E. B., Speizer, F. E., et al. (2001). The effect of fruit and vegetable intake on risk for coronary heart disease. Annals of Internal Medicine, 134(12), 1106-1114.

Kahneman, D., \& Tversky, A. (1979). Prospect theory. An analysis of decisions under risk. Econometrica: Journal of the Econometric Society, 47, 263-291.

Kees, J. (2011). Advertising framing effects and consideration of future consequences. The Journal of Consumer Affairs, 45(1), 7-32.
Kopelman, P. (2007). Health risks associated with overweight and obesity. Obesity Reviews, 8(s1), 13-17.

Kumanyika, S. K., Bowen, D., Rolls, B. J., Van Horn, L., Perri, M. G., Czajkowski, S. M., et al. (2000). Maintenance of dietary behavior change. Health Psychology, 19(1S), 42.

Levin, I. P., Schneider, S. L., \& Gaeth, G. J. (1998). All frames are not created equal. A typology and critical analysis of framing effects. Organizational Behavior and Human Decision Processes, 76(2), 149-188.

Liu, R. H. (2003). Health benefits of fruit and vegetables are from additive and synergistic combinations of phytochemicals. The American Journal of Clinical Nutrition, 78(3), 517S-520S.

Lo, S. H., Smith, S. G., Taylor, M., Good, A., \& von Wagner, C. (2012). The effect of temporal framing on behavioral intentions, expectations, and behavior. The case of healthy eating. Journal of Applied Biobehavioral Research, 17(3), 202-213.

Lobstein, T., Rigby, N., \& Leach, R. (2005). EU platform on diet. In Physical activity and health, IOTF EU platform briefing paper, in collaboration with the European Association for the Study of Obesity, International Obesity Task Force, London.

Luszczynska, A., Tryburcy, M., \& Schwarzer, R. (2007). Improving fruit and vegetable consumption. A self-efficacy intervention compared with a combined self-efficacy and planning intervention. Health Education Research, 22(5), 630-638.

Mann, T., Sherman, D., \& Updegraff, J. (2004). Dispositional motivations and message framing. A test of the congruency hypothesis in college students. Health Psychology, 23, 330-334.

Masalu, J. R., \& Åstrøm, A. N. (2001). Predicting intended and self-perceived sugar restriction among Tanzanian students using the theory of planned behavior. Journal of Health Psychology, 6(4), 435-445.

Miller, R., Benelam, B., Stanner, S. A., \& Buttriss, J. L. (2013). Is snacking good or bad for health. An overview. Nutrition Bulletin, 38(3), 302-322.

Ness, A. R., \& Powles, J. W. (1997). Fruit and vegetables, and cardiovascular disease. A review. International Journal of Epidemiology, 26(1), 1-13.

Pavey, L., \& Churchill, S. (in press). Promoting the avoidance of high-calorie snacks. Priming autonomy moderates message framing effects. PLOS ONE.

Petty, R. E., \& Cacioppo, J. T. (1986). The elaboration likelihood model of persuasion (pp. 1-24). New York: Springer.

Povey, R., Conner, M., Sparks, P., James, R., \& Shepherd, R. (2000). Application of the theory of planned behaviour to two-health-related dietary behaviours. Roles of perceived control and self-efficacy. British Journal of Health Psychology, 5, 121-139.

Richert, J., Reuter, T., Wiedemann, A. U., Lippke, S., Ziegelmann, J., \& Schwarzer, R. (2010). Differential effects of planning and self-efficacy on fruit and vegetable consumption. Appetite, 54, 611-614.

Rothman, A. J., Bartels, R. D., Wlaschin, J., \& Salovey, P. (2006). The strategic use of gain- and loss-framed messages to promote healthy behavior. How theory can inform practice. The Journal of Communication, 56(s1), S202-S220.

Rothman, A. J., \& Salovey, P. (1997). Shaping perceptions to motivate healthy behavior The role of message framing. Psychological Bulletin, 121(1), 3.

Rothman, A. J., Wlaschin, J., Bartels, R., Latimer, A., \& Salovey, P. (2008). How persons and situations regulate message framing effects. The study of health behavior. In A. Elliot (Ed.), Handbook of approach and avoidance motivation (pp. 475-486). Mahwah, NJ: LEA.

Saksvig, B. I., Gittelsohn, J., Harris, S. B., Hanley, A. J., Valente, T. W., \& Zinman, B. (2005) A pilot school-based healthy eating and physical activity intervention improves diet, food knowledge, and self-efficacy for native Canadian children. The Journal of Nutrition, 135(10), 2392-2398.

Salovey, P., Rothman, A. J., \& Rodin, J. (1998). Health behavior. In D. T. Gilbert, S. T. Fiske, \& G. Lindzey (Eds.), The handbook of social psychology (4th ed., Vol. 2, pp. 633-683). Boston, MA, USA: McGraw-Hill.

Schwarzer, R. (2008). Modeling health behavior change. How to predict and modify the adoption and maintenance of health behaviors. Applied Psychology: An International Review, 57, 1-29.

Spiegel, S., Grant-Pillow, H., \& Higgins, E. T. (2004). How regulatory fit enhances motivational strength during goal pursuit. European Journal of Social Psychology, 34(1), 39-54.

Strecher, V. J., DeVellis, B. M., Becker, M. H., \& Rosenstock, I. M. (1986). The role of self-efficacy in achieving health behavior change. Health Education \& Behavior, 13(1), 73-92.

Tabassum, F. (2009). Adult anthropometric measures, overweight and obesity. In R. Craig \& V. Hirani (Eds.), Health Survey for England 2009 (Vol. 1, pp. 113-136). Health and lifestyles. Leeds, UK: The NHS Information Centre.

Trope, Y., \& Liberman, N. (2000). Temporal construal and time-dependent changes in preference. Journal of Personality and Social Psychology, 79, 876-889.

Trope, Y., \& Liberman, N. (2003). Temporal construal. Psychological Review, 110(3), 403.

Trope, Y., \& Liberman, N. (2010). Construal-level theory of psychological distance. Psychological Review, 117, 440-463.

Tversky, A., \& Kahneman, D. (1981). The framing of decisions and the psychology of choice. Science, 211, 453-458.

van 't Riet, J., Ruiter, R. A. C., Werrij, M. Q., \& de Vries, H. (2009). Investigating message-framing effects in the context of a tailored intervention promoting physical activity. Health Education Research, 25(2), 343-354.

van 't Riet, J., Ruiter, R. A. C., Werrij, M. Q., \& de Vries, H. (2010). Self-efficacy moderates message-framing effects. The case of skin-cancer detection. Psychology and Health, $25,339-349$.

Wadden, T. A., \& Letizia, K. A. (1992). Predictors of attrition and weight loss in patients treated by moderate and severe caloric restriction. In T. A. Wadden \& T. B. VanItallie (Eds.), Treatment of the seriously obese patient (pp. 383-410, xix). New York, NY, US: Guilford Press. 524 pp. 
Wangberg, S. C. (2008). An Internet-based diabetes self-care intervention tailored to self-efficacy. Health Education Research, 23(1), 170-179.

Werrij, M. Q., Ruiter, R. A., van 't Riet, J., \& de Vries, H. (2011). Self-efficacy as a potential moderator of the effects of framed health messages. Journal of Health Psychology, 16, 199-207.
Wiseman, M. (2008). The Second World Cancer Research Fund/American Institute for Cancer Research Expert Report. Food, nutrition, physical activity, and the prevention of cancer. A global perspective. The Proceedings of the Nutrition Society, 67(03), 253-256. 